\title{
The cranium of Sts 5 ('Mrs Ples') in relation to sexual dimorphism of Australopithecus africanus
}

AUTHORS:
Gaokgatlhe M. Tawane ${ }^{1}$
J. Francis Thackeray ${ }^{2}$

\section{AFFILIATIONS:}

${ }^{1}$ Ditsong National Museum of Natural History, Pretoria, South Africa

${ }^{2}$ Evolutionary Studies Institute, School of Geosciences, University of the Witwatersrand, Johannesburg, South Africa

\section{CORRESPONDENCE TO:}

Francis Thackeray

\section{EMAIL:}

francis.thackeray@wits.ac.za

\section{KEYWORDS:}

Hominini; human evolution;

Pleistocene; Sterkfontein;

South Africa

\section{HOW TO CITE:}

Tawane GM, Thackeray JF. The cranium of Sts 5 ('Mrs Ples') in relation to sexual dimorphism of Australopithecus africanus. S Afr J Sci. 2018;114(1/2), Art \#a0249, 4 pages. http://dx.doi. org/10.17159/sajs.2018/a0249

(C) 2018. The Author(s). Published under a Creative Commons Attribution Licence.
Fossil Sts 5 ('Mrs Ples') is a Plio-Pleistocene cranium assigned to Australopithecus africanus. It was discovered in April 1947 by Robert Broom and John Robinson at Sterkfontein in the Gauteng Province, situated in the Cradle of Humankind in South Africa. ${ }^{1}$ It is thought to date to at least 2.1 mya2-4, probably closer to 2.5 mya. Broom had initially referred to such specimens from Sterkfontein as Plesianthropus (where 'plesi' refers to 'almost', and 'anthropus' to 'human').

Broom ${ }^{1,5}$ suggested that the edentulous specimen represented a female individual on the basis of small canine sockets, but in 1947 he did not have a substantial comparative sample for $A$. africanus. He considered Sts 5 to be an adult based on his claim that cranial sutures appeared to be closed, assuming that suture closure could be used to estimate developmental age. The identification of Sts 5 as the cranium of a female adult is still the subject of ongoing debate. Resolution of this issue is important for an understanding of sexual dimorphism and ontogeny in $A$. africanus.

The debate concerning the developmental age and sex of Sts 5 can be summarised in terms of a diversity of views held in recent decades. Rak ${ }^{6}$ used the presence of facial anterior pillars to suggest that Sts 5 represented a male individual. Lockwood ${ }^{7}$ examined variability in facial anatomy in more than 12 specimens of $A$. africanus to try to distinguish between female and male individuals, but was not in a position to be certain as to whether 'Mrs Ples' was the cranium of a female individual, as suggested initially by Broom, or that of a male individual, as contended by Rak.

With regard to the developmental age of Sts 5, Thackeray et al. ${ }^{8}$ used CT scans of the roots of dentition to suggest that the individual was adolescent. By contrast, Bonmati et al. ${ }^{9}$ concluded that the individual was adult at the time of death, while Villmoare et al. ${ }^{10}$ suggested that 'Mrs Ples' was senescent. Grine et al..$^{11}$ stated: 'There is no evidence to contradict the assertion that "Mrs Ples" is an adult female'.

Here, we do not attempt to resolve the issue as to whether Sts 5 represents an adult or an adolescent individual. Instead, we address the question as to whether Sts 5 is the cranium of a small male individual distinct from that of a large female individual, using alveolar canine dimensions and a re-examination of Lockwood's ${ }^{7}$ craniofacial data as an expression of sexual dimorphism in $A$. africanus.

\section{Canine sockets and alveolar bone loss}

Broom's ${ }^{1,5}$ suggestion that Sts 5 represents a female individual, based on a small canine socket, needs to be examined in the context of post-mortem damage. After mechanical preparation of the cranium, using hammer and chisel, Broom et al..$^{12}$ measured the buccolingual (BL) and mesiodistal (MD) canine socket diameters as $9.0 \mathrm{~mm}$ and $7.6 \mathrm{~mm}$, respectively.

Unfortunately, acetic acid was used at some stage of preparation, as is evident from acid damage to the petrosal bones within the cranium. If acid caused such damage to substantially thick petrosal bones, it is likely that (at some time since 1950) acetic acid preparation also caused damage to alveolar bone associated with the canine sockets. Such acid damage would have led to a reduction of canine socket diameters because the roots of the canines (and the associated sockets) are conical.

In 2012, the BL and MD diameters for the right canine alveolar socket were given by Grine et al..$^{11}$ as $7.2 \mathrm{~mm}$ and $6.9 \mathrm{~mm}$, respectively. These values correspond closely to a BL value of $7.0 \mathrm{~mm}$ given by Thackeray ${ }^{13}$ and a MD dimension of $6.9 \mathrm{~mm}$ obtained in this study. The reduction in the reported BL diameter, from $9 \mathrm{~mm}$ to $7.2 \mathrm{~mm}$, could relate to post-mortem damage to the conical sockets, of the kind associated with acid preparation of the fossil. Villmoare et al. ${ }^{10}$ confirmed that some degree of alveolar bone loss had occurred in the case of Sts 5 .

It is not known to what extent Broom's mechanical preparation of the maxilla contributed to the damage of original alveolar bone adjacent to the canine socket. It is also not certain to what extent some degree of predepositional bone loss may have occurred after the canine teeth had broken, prior to the sockets being filled with sediment which became calcified. However, assuming that original measurements by Broom et al. ${ }^{12}$ were accurate, it is apparent that in 1950 the conical canine alveolar sockets were larger than they are currently. We suggest that this difference is a result of acid preparation sometime after 1950. These observations are relevant to the identification of the sex of Sts 5, compared to other cranial specimens of $A$. africanus that have been identified as belonging to either male or female individuals.

The measurement of $9 \mathrm{~mm}$ by Broom et al. ${ }^{12}$ for the BL diameter of Sts 5 is larger than the BL diameter of $8 \mathrm{~mm}$ for a definite male specimen of $A$. africanus (Stw 505), and almost as large as the BL diameters for another male adult, TM 1511, estimated as $10.2 \mathrm{~mm}$ for the left canine ${ }^{12}$ and $10.5 \mathrm{~mm}$ for the right canine ${ }^{11}$. Discovered in 1936, TM 1511 was not prepared in acetic acid.

Relationships between $\mathrm{BL}$ and MD canine diameters for presumed male and female specimens of $A$. africanus are shown in Figure 1, based partly on data presented by Grine et al. ${ }^{11}$ but (for the first time, in this study) including the position of Sts 5 based on BL and MD diameter measurements published by Broom et al. ${ }^{12}$ in 1950 and recorded before the damage associated with acetic acid preparation. According to these data, the canine diameter measurements of Sts 5 are consistent with the hypothesis that 'Mrs Ples' indeed represents a male individual. The 
data for $\mathrm{BL}$ and $\mathrm{MD}$ diameters shown in Figure 1 counter the statement by Grine et al. ${ }^{11}$ that 'there is no evidence to contradict the assertion' that Sts 5 represents a female individual.

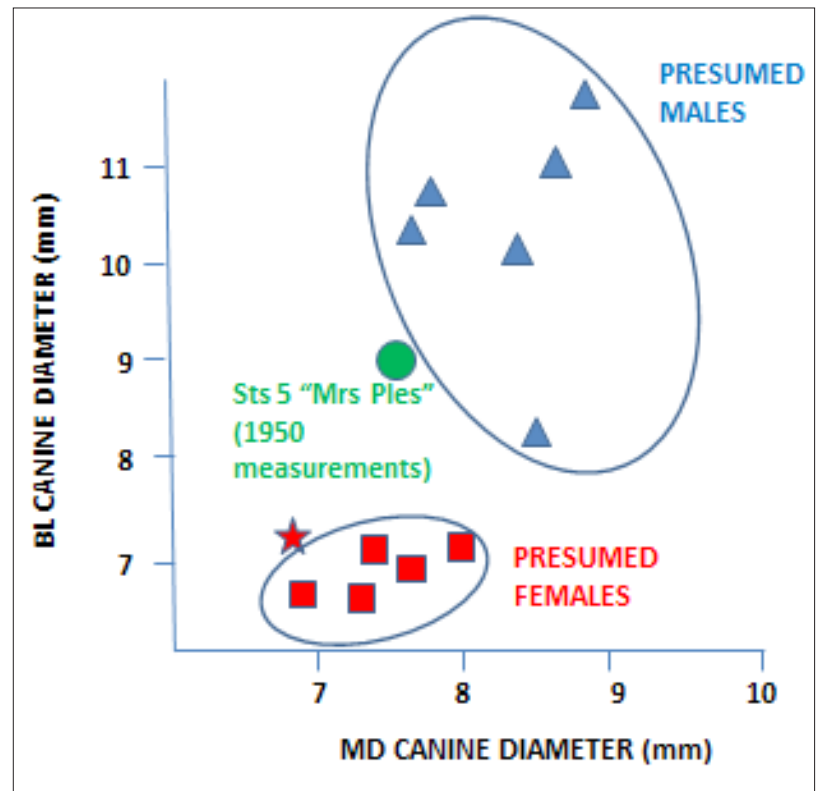

Figure 1: Relationship between buccolingual (BL) and mesiodistal (MD) diameters for conical canine sockets, based in part on data for presumed male individuals (blue triangles) and presumed female individuals (red squares) of Australopithecus africanus, published by Grine et al. ${ }^{11}$ The green circle represents MD and BL measurements for Sts 5 as published by Broom et al. ${ }^{12}$, most probably taken before damage and alveolar bone loss occurred. According to these data, Sts 5 is more likely to belong to a small male individual than a female individual, as proposed by Grine et al. ${ }^{11}$ The red star represents measurements of Sts 5 given by Grine et al. ${ }^{11}$, probably obtained after damage caused by digestion of cranial bone in acetic acid. Presumed male individuals are Stw 505, TM 1511, Sts 52, Stw 183, Stw 252, Stw 369 and presumed female individuals are Sts 71 , Sts 17 , Sts 53 , Stw 13 , Stw $73 .^{11}$

\section{Sexual dimorphism in $A$. africanus}

Sexual dimorphism of the facial anatomy of $A$. africanus was investigated by Lockwood who recognised Sts 71 as a female adult and Stw 505 as a large male adult; and, on the basis of many facial variables taken together, Lockwood $^{7}$ concluded that the sex of the relatively small Sts 5 individual was 'indeterminate'. This problem relates at least in part to the challenge of distinguishing a relatively large female from a small male individual. ${ }^{13}$

Certain features can help to address this problem. Among the most remarkable facial features of Sts 5 is its prominent glabella which Lockwood ${ }^{7}$ described as 'marked' (as in the case of the male Stw 505), distinct from the slight glabellar prominence in Sts 71 (identified as female). In fact, Lockwood ${ }^{7}$ stated that the glabellar as well as the supraorbital morphology of Sts 5 indicated that this specimen was one of the 'best candidates' for being male (our emphasis).

Lockwood ${ }^{7}$ calculated mean values and standard deviations for 21 craniofacial dimensions for a sample of 13 specimens of $A$. africanus housed at the University of the Witwatersrand and the Ditsong National Museum of Natural History (formerly the Transvaal Museum), including Sts 5 (Table 1). We have calculated standardised z-scores for the facial dimensions of Sts 5 using the means and standard deviations for these dimensions in Sts 5 and the other $A$. africanus specimens measured by Lockwood ${ }^{7}$. The z-scores are calculated by:
$Z=[x-$ mean for $A$. africanus dimensions $] /$ standard deviation for $A$. africanus dimensions, where $x$ is the dimension for Sts 5 , for each of the 21 variables listed in Table 1.

Table 1: Measurements of 21 craniometric distances of Sts 5 in relation to the means and standard deviations for corresponding variables for specimens of Australopithecus africanus measured by Lockwood?. The $z$-values for Sts 5 in bold are relatively large in relation to the $z$-values for Sts 5 for other cranial dimensions.

\begin{tabular}{|c|c|c|c|c|c|}
\hline \multicolumn{2}{|c|}{ Cranio-facial measurement } & \multirow{2}{*}{$\begin{array}{l}\begin{array}{l}\text { Sts } 5 \\
(\mathrm{~mm})\end{array} \\
30.5\end{array}$} & \multirow{2}{*}{$\begin{array}{c}\begin{array}{c}\text { Mean } \boldsymbol{A} . \\
\text { africanus } \\
(\mathbf{m m})\end{array} \\
32.2\end{array}$} & \multirow{2}{*}{\begin{tabular}{|c}
$\begin{array}{c}\text { Standard } \\
\text { deviation } \\
\text { (mm) }\end{array}$ \\
2.8
\end{tabular}} & \multirow{2}{*}{$\begin{array}{c}\text { for } \\
\text { Sts } 5 \\
-0.607\end{array}$} \\
\hline Orbital height & $\mathrm{ORBH}$ & & & & \\
\hline Glabellar height & GLAH & 75.3 & 82.1 & 10.7 & -0.635 \\
\hline Upper facial height & UPFH & 70 & 77.8 & 10 & -0.789 \\
\hline Nasal height & NASH & 47.6 & 54.1 & 7.1 & -0.915 \\
\hline Orbito-alveolar height & OALH & 49 & 49.1 & 5.3 & -0.019 \\
\hline Orbito-jugal height & OJUH & 57.8 & 53.8 & 6.6 & 0.606 \\
\hline Foraminal height & FORH & 38 & 35.9 & 3 & 0.700 \\
\hline Malar depth & MALH & 25.1 & 26.4 & 3.8 & -0.342 \\
\hline Alveolar height & ALVH & 30 & 25.7 & 3.2 & 1.343 \\
\hline Superior facial breadth & SUFB & 95.1 & 95.5 & 8.2 & -0.048 \\
\hline $\begin{array}{l}\text { Anterior interorbital } \\
\text { breadth }\end{array}$ & ITOB & 15.5 & 16 & 1.5 & -0.333 \\
\hline Bimaxillary breadth & BMAB & 105 & 99.7 & 8.1 & 0.654 \\
\hline Interforaminal breadth & IFOB & 43.6 & 44.8 & 6.4 & -0.187 \\
\hline Nasal aperture breadth & NASB & 27 & 24.9 & 2.5 & 0.840 \\
\hline Snout breadth & SNOB & 45.6 & 47 & 5 & -0.280 \\
\hline $\begin{array}{l}\text { Anterior maxillo-alveolar } \\
\text { breadth }\end{array}$ & ANMB & 45.4 & 46.3 & 3.3 & -0.272 \\
\hline Maxillo-alveolar breadth & MAXB & 65.4 & 64.9 & 4.7 & 0.106 \\
\hline Anterior palatal breadth & APAB & 33 & 32.5 & 2.6 & 0.192 \\
\hline Palatal breadth & PALB & 36.4 & 35.1 & 3.8 & 0.342 \\
\hline Maxillo-alveolar length & MAXL & 50.4 & 51.4 & 2.2 & -0.454 \\
\hline $\begin{array}{l}\text { Post-canine maxillo- } \\
\text { alveolar length }\end{array}$ & PMXL & 42 & 41.2 & 2.1 & 0.380 \\
\hline
\end{tabular}

Five craniofacial dimensions are relatively large in Sts 5 : alveolar height $(\mathrm{ALVH})$, foraminal height, nasal breadth, bi-maxillary breadth and orbitojugal height. Results are presented in Figure 2 for ALVH and bimaxillary breadth, as two examples.

ALVH in Sts 5 has a value of $30 \mathrm{~mm}$ compared with a mean value of $25.7 \pm 3.2 \mathrm{~mm}(n=11)$ for specimens of the species examined by Lockwood ${ }^{7}$. ALVH in $A$. africanus ranges between $21.1 \mathrm{~mm}$ and $30.0 \mathrm{~mm}$. Thus Sts 5 has the largest ALVH dimension in this sample of the species. ALVH in Sts $5(30 \mathrm{~mm})$ is not only larger than the ALVH value of $23 \mathrm{~mm}$ in Sts 71 (identified as a female adult), but also larger than the ALVH value of $29 \mathrm{~mm}$ in Stw 505 identified as a large male adult. This is also reflected by standardised z-scores (Figure 2). Similarly, in terms of bimaxillary breadth, Sts 5 appears to be closer to that of a male individual (Stw 505), as shown in Figure 2. 


\section{A. africanus}

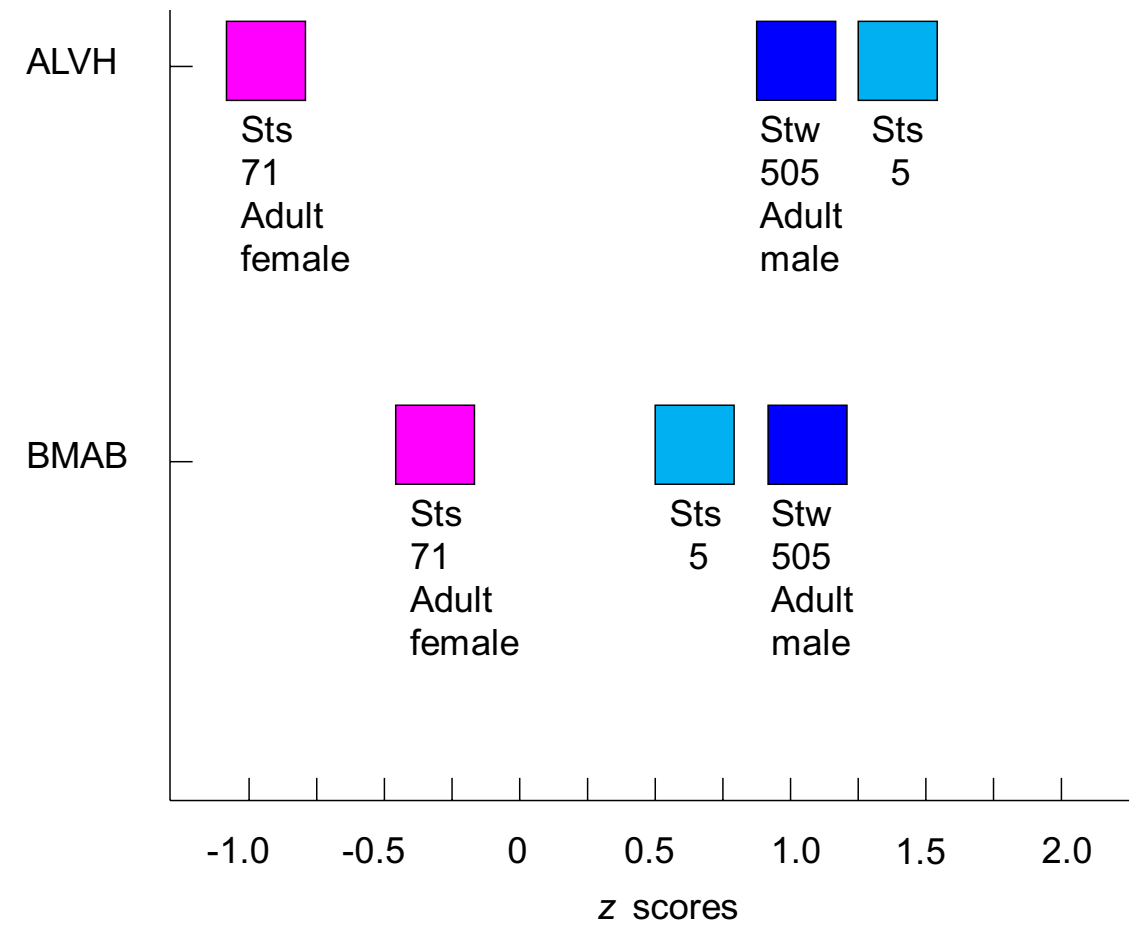

Figure 2: Standardised z-values for Sts 5, compared to other specimens of Australopithecus africanus, based on means and standard deviations of alveolar height (ALVH) and bi-maxillary breadth (BMAB).

\section{Conclusion}

Both age and sex are factors that would have contributed to variation in growth and development of crania of australopithecines. ${ }^{13-16}$ If Sts 5 was adolescent, as suggested by Thackeray et al. ${ }^{8}$, this would partially account for the relatively small dimensions of some of the facial variables of this specimen, for example nasion height and upper posterior facial height. However, the relatively large values of certain facial variables of 'Mrs Ples' (Figure 2, Table 1) - for example, ALVH as well as other dimensions such as foraminal height, nasal breadth, bi-maxillary breadth and orbito-jugal height - can partially be accounted for in terms of Sts 5 belonging to a male individual. The fact that some variables of Sts 5 are relatively large for Sts 5 , whereas others are relatively small (as compared to the mean values for $A$. africanus) could be because of a combination of factors associated with both ontogeny and sexual dimorphism.

Despite observations by Villmoare et al. ${ }^{10}$ regarding remodelling of anterior maxillary bone, the prominent glabella of Sts 5 and its supraorbital morphology are not inconsistent with it being male, as noted by Lockwood $^{7}$. Furthermore, the indisputable evidence for open cranial sutures ${ }^{17}$ is not inconsistent with the hypothesis that Sts 5 was adolescent at the time of death. These observations, together with the relatively large BL measurement for the canine alveolar diameter (as published originally by Broom et al. ${ }^{2}$ ), refute the statement that 'there is no evidence to contradict the assertion that 'Mrs Ples' is an adult female'11.

On the basis of the data presented here, we conclude that Sts 5 is a small male rather than a large female individual. This conclusion is relevant to an understanding of Sts 5 in the context of sexual dimorphism in A. africanus.

\section{Acknowledgements}

J.F.T. thanks the Andrew W. Mellon Foundation, the National Research Foundation (South Africa) and the DST/NRF Centre of Excellence in
Palaeosciences for their support. We thank J. Braga, C. Dean, A.L. Dinat and A.D. Botham for helpful comments.

\section{References}

1. Broom R. Discovery of a new skull of the South African ape-man, Plesianthropus. Nature. 1947;159:672.

2. Partridge TC. Dating of the Sterkfontein hominids: Progress and possibilities. Trans R Soc S Afr. 2005;60(2):107-109. https://dx.doi. org/10.1080/00359190509520486

3. Pickering R, Kramers JD. Re-appraisal of the stratigraphy and dating of new U-Pb dates for the Sterkfontein hominin site, South Africa. J Hum Evol. 2010;59(1):70-86. http://dx.doi.org/10.1016/.j.jhevol.2010.03.014

4. Thackeray JF, Dupont LM. Last recorded occurrence of Australopithecus africanus and climatic change in southern Africa. S Afr J Sci. 2006;102:50.

5. Broom R. The most perfect pre-human skull ever found. The discovery of a nearly perfect 'missing link' skull. Illustrated London News. 1947;210:508509 .

6. Rak R. The australopithecine face. New York: Academic Press; 1983.

7. Lockwood CA. Sexual dimorphism in the face of Australopithecus africanus. Am J Phys Anthropol. 1999;108(9):97-127. http://dx.doi.org/10.1002/ (SICI)1096-8644(199901)108:1 <97::AID-AJPA6>3.0.C0;2-0

8. Thackeray JF, Braga J, Treil J, Niksch N, Labuschagnge JH. 'Mrs Ples' (Sts 5) from Sterkfontein: An adolescent male? S Afr J Sci. 2002;98(1):21-22.

9. Bonmati A, Arsuaga J-L, Lorenzo C. Revisiting the developmental age-atdeath of the "Mrs Ples" (Sts 5) and Sts 14 specimens from Sterkfontein (South Africa): Do they belong to the same individual? Anat Rec. 2008;291(12):1707-1722. http://dx.doi.org/10.1002/ar.20795

10. Villmoare B, Kujkendall K, Rae TC, Brimacombe CS. Continuous dental eruption identifies Sts 5 as the developmentally oldest fossil hominin and informs the taxonomy of Australopithecus africanus. J Hum Evol. 2013;65:798-805. http://dx.doi.org/10.1016/.j.jhevol.2013.09.007 
11. Grine FE, Weber GW, Plavcan JM, Benazzi S. Sex at Sterkfontein: 'Mrs Ples' is still an adult female. J Hum Evol. 2012;62(5):593-604. http://dx.doi. org/10.1016/j.jhevol.2012.01.010

12. Broom R, Robinson JT, Schepers GWH. Further evidence of the structure of the Sterkfontein ape-man Plesianthropus. Transv Mus Mem. 1950;4(4):1113

13. Thackeray JF. 'Mrs Ples' from Sterkfontein: Small male or large female? S Afr Archaeol Bull. 2000;55:155-158. http://dx.doi.org/10.10.2307/3888964

14. Ackermann RR, Krowitz GE. Morphological and craniofacial shape and growth patterns in Australopithecus africanus. Am J Phys Anthropol. 2000;30:91.
15. Lockwood CA, Mentor CG, Moggi-Ceechi J, Keyser A. Extended male growth in a fossil hominin species. Science. 2007;318(5855):1443-1446. http:// dx.doi.org/10.10.1126/science.1149211

16. Prat S, Thackeray JF. Position des lignes temporales sur le cranium de "Mrs" Ples (A. africanus): une attribution sexuelle est-elle possible? [Possible position of the temporal lines on the cranium of 'Mrs' Ples (A. africanus): Is sexual determination possible?] C R Acad Sci ll. 2001;332:403-409. French. http://dx.doi.org/10.1016/S1251-8050(01)01548-8

17. Potze S, Thackeray JF. Temporal lines and open sutures revealed on cranial bone adhering to matrix associated with Sts 5 ("Mrs Ples"), Sterkfontein South Africa. J Hum Evol. 2010;58(6):533-535. http://dx.doi.org/10.1016/j. jhevol.2009.11.005 